\title{
Conceito e diagnóstico
}

José Alberto Del Porto'

\section{Resumo}

Este artigo revê o conceito de depressão e a nosologia contemporânea dos estados depressivos e seus diferentes subtipos. São discutidos aspectos relativos ao curso (formas agudas vs crônicas da doença, padrão sazonal), características fenomenológicas (melancolia, quadros psicóticos, quadros atípicos, formas catatônicas) da doença, assim como a importância e o significado das alterações psicomotoras para o diagnóstico das chamadas depressões "endógenas" ou "vitais", de acordo com trabalhos contemporâneos (como os de Parker e Widlöcher). Este trabalho aborda também as fronteiras da depressão com o transtorno bipolar, os transtornos de personalidade, a desmoralização e os estados de luto normal, assim como os limites com outras doenças e estados induzidos por drogas.

\section{Descritores}

Depressão; transtornos do humor; melancolia; depressão atípica; padrão sazonal; diagnóstico; nosologia

\section{Abstract}

This paper reviews the concept of depression and the contemporary nosology of depressive states with their different subtypes. Course (acute vs chronic depressions, seasonal pattern) and phenomenological characteristics (melancholic, atypical, psychotic and catatonic features) are discussed, as well as the importance and meaning of psychomotor disturbance for the diagnosis of the so-called "endogenous" or "vital" depression, in accordance with contemporary authors (Parker and Widlöcher). This paper also discusses the boundaries of depression with bipolar disorder, personality disorders, demoralisation and normal feelings of sadness, as well as the limits with other clinical diseases and drug induced conditions.

\section{Keywords}

Depression; mood disorders; melancholia; atypical depression; seasonal pattern; diagnosis; nosology

\section{Significados do termo "depressão"}

$\mathrm{O}$ termo depressão, na linguagem corrente, tem sido empregado para designar tanto um estado afetivo normal (a tristeza), quanto um sintoma, uma síndrome e uma (ou várias) doença(s).

Os sentimentos de tristeza e alegria colorem o fundo afetivo da vida psíquica normal. A tristeza constitui-se na resposta humana universal às situações de perda, derrota, desapontamento e outras adversidades. Cumpre lembrar que essa resposta tem valor adaptativo, do ponto de vista evolucionário, uma vez que, através do retraimento, poupa energia e recursos para o futuro. Por outro lado, constitui-se em sinal de alerta, para os demais, de que a pessoa está precisando de companhia e ajuda. As reações de luto, que se estabelecem em resposta à perda de pessoas queridas, caracterizam-se pelo sentimento de profunda tristeza, exacerbação da atividade simpática e inquietude. As reações de luto normal podem estender-se até por um ou dois anos, devendo ser diferenciadas dos quadros depressivos propriamente ditos. No luto normal a pessoa usualmente preserva certos interesses e reage positivamente ao ambiente, quando devidamente estimulada. Não se observa, no luto, a ini- bição psicomotora característica dos estados melancólicos. Os sentimentos de culpa, no luto, limitam-se a não ter feito todo o possível para auxiliar a pessoa que morreu; outras idéias de culpa estão geralmente ausentes.

Enquanto sintoma, a depressão pode surgir nos mais variados quadros clínicos, entre os quais: transtorno de estresse pós-traumático, demência, esquizofrenia, alcoolismo, doenças clínicas, etc. Pode ainda ocorrer como resposta a situações estressantes, ou a circunstâncias sociais e econômicas adversas.

Enquanto síndrome, a depressão inclui não apenas alterações do humor (tristeza, irritabilidade, falta da capacidade de sentir prazer, apatia), mas também uma gama de outros aspectos, incluindo alterações cognitivas, psicomotoras e vegetativas (sono, apetite).

Finalmente, enquanto doença, a depressão tem sido classificada de várias formas, na dependência do período histórico, da preferência dos autores e do ponto de vista adotado. Entre os quadros mencionados na literatura atual encontram-se: transtorno depressivo maior, melancolia, distimia, depressão integrante do transtorno bipolar tipos I e II, depressão como parte da ciclotimia, etc.

1. Professor Titular do Departamento de Psiquiatria da Universidade Federal de São Paulo. 


\section{Descrição clínica}

As descrições feitas por Kraepelin, dos estados depressivos e maníacos, na oitava edição de seu tratado, são insuperáveis pela clareza e precisão. Felizmente encontra-se disponível uma reedição recente desse trabalho, em tradução inglesa, ${ }^{1}$ o que torna sua leitura mais facilmente acessível. De muito interesse é o artigo clássico de Falret, sobre a "folie circulaire", marco na história da doença maníaco-depressiva, datado de 1854 e recentemente republicado pelo American Journal of Psychiatry, com comentários de Marc Sedler. ${ }^{2}$ Igualmente interessantes são as descrições de Bleuler, em seu Tratado de Psiquiatria (atualizado por Manfred Bleuler), que conta com traduções em espanhol e mesmo em português. ${ }^{3}$

\section{Aspectos gerais}

Embora a característica mais típica dos estados depressivos seja a proeminência dos sentimentos de tristeza ou vazio, nem todos os pacientes relatam a sensação subjetiva de tristeza. Muitos referem, sobretudo, a perda da capacidade de experimentar prazer nas atividades em geral e a redução do interesse pelo ambiente. Freqüentemente associa-se à sensação de fadiga ou perda de energia, caracterizada pela queixa de cansaço exagerado. Alguns autores ${ }^{4,5}$ enfatizam a importância das alterações psicomotoras, em particular referindo-se à lentificação ou retardo psicomotor. Este tópico será abordado mais detidamente no item referente à conceituação da "melancolia".

No diagnóstico da depressão levam-se em conta: sintomas psíquicos; fisiológicos; e evidências comportamentais.

\section{Sintomas psíquicos}

- Humor depressivo: sensação de tristeza, autodesvalorização e sentimentos de culpa.

Os pacientes costumam aludir ao sentimento de que tudo lhes parece fútil, ou sem real importância. Acreditam que perderam, de forma irreversível, a capacidade de sentir alegria ou prazer na vida. Tudo lhes parece vazio e sem graça, o mundo é visto "sem cores", sem matizes de alegria. Em crianças e adolescentes, sobretudo, o humor pode ser irritável, ou "rabugento", ao invés de triste. Certos pacientes mostram-se antes "apáticos" do que tristes, referindo-se muitas vezes ao "sentimento da falta de sentimentos". Constatam, por exemplo, já não se emocionarem com a chegada dos netos, ou com o sofrimento de um ente querido, e assim por diante.

$\mathrm{O}$ deprimido, com freqüência, julga-se um peso para os familiares e amigos, muitas vezes invocando a morte para aliviar os que o assistem na doença.

São frequientes e temíveis as idéias de suicídio. As motivações para o suicídio incluem distorções cognitivas (perceber quaisquer dificuldades como obstáculos definitivos e intransponíveis, tendência a superestimar as perdas sofridas) e ainda o intenso desejo de pôr fim a um estado emocional extremamente penoso e tido como interminável. Outros ainda buscam a morte como forma de expiar suas supostas culpas. Os pensamentos de suicídio variam desde o remoto desejo de estar simplesmente morto, até planos minuciosos de se matar (estabelecendo o modo, o momento e o lugar para o ato). Os pensamentos relativos à morte devem ser sistematicamente inves- tigados, uma vez que essa conduta poderá prevenir atos suicidas, dando ensejo ao doente de se expressar a respeito.

- Redução da capacidade de experimentar prazer na maior parte das atividades, antes consideradas como agradáveis. As pessoas deprimidas podem relatar que já não se interessam pelos seus passatempos prediletos. As atividades sociais são frequientemente negligenciadas, e tudo lhes parece agora ter o peso de terríveis "obrigações".

- Fadiga ou sensação de perda de energia. A pessoa pode relatar fadiga persistente, mesmo sem esforço físico, e as tarefas mais leves parecem exigir esforço substancial. Lentifica-se o tempo para a execução das tarefas.

- Diminuição da capacidade de pensar, de se concentrar ou de tomar decisões. Decisões antes quase automáticas parecem agora custar esforços intransponíveis. Um paciente pode se demorar infindavelmente para terminar um simples relatório, pela incapacidade em escolher as palavras adequadas. $\mathrm{O}$ curso do pensamento pode estar notavelmente lentificado. Professores experientes queixam-se de não conseguir preparar as aulas mais rotineiras; programadores de computadores pedem para ser substituídos pela atual "incompetência"; crianças e adolescentes têm queda em seus rendimentos escolares, geralmente em função da fatigabilidade e déficit de atenção, além do desinteresse generalizado.

\section{Sintomas fisiológicos}

- alterações do sono (mais freqüentemente insônia, podendo ocorrer também hipersonolência). A insônia é, mais tipicamente, intermediária (acordar no meio da noite, com dificuldades para voltar a conciliar o sono), ou terminal (acordar mais precocemente pela manhã). Pode também ocorrer insônia inicial. Com menor freqüência, mas não raramente, os indivíduos podem se queixar de sonolência excessiva, mesmo durante as horas do dia.

- alterações do apetite (mais comumente perda do apetite, podendo ocorrer também aumento do apetite). Muitas vezes a pessoa precisa esforçar-se para comer, ou ser ajudada por terceiros a se alimentar. As crianças podem, pela inapetência, não ter o esperado ganho de peso no tempo correspondente. Algumas formas específicas de depressão são acompanhadas de aumento do apetite, que se mostra caracteristicamente aguçado por carboidratos e doces.

- redução do interesse sexual

Evidências comportamentais

- retraimento social

- crises de choro

- comportamentos suicidas

- Retardo psicomotor e lentificação generalizada, ou agitação psicomotora. Freqüentemente os pacientes se referem à sensação de peso nos membros, ou ao "manto de chumbo" que parecem estar carregando. Em recente revisão da literatura sobre os estados depressivos, o item "retardo psicomotor" foi o denominador comum, em nove sistemas classificatórios, como traço definidor da melancolia. Na Austrália, Gordon Parker e colaboradores $^{5}$ propuseram, para o diagnóstico da melancolia, um sistema baseado não em "sintomas" (subjetivos), mas em "sinais" (características objetivas, observáveis): o sistema "core", que 
tem sido cada vez mais utilizado pelos pesquisadores nessa área. Na França, Daniel Widlöcher ${ }^{4}$ e colaboradores, na Salpêtrière, desenvolveram uma escala especificamente destinada a medir o retardo psicomotor ("échelle de ralentissement dépressif" da Salpêtrière). Deve-se ainda lembrar, no diagnóstico das depressões, que algumas vezes o quadro mais típico pode ser mascarado por queixas proeminentes de dor crônica (cefaléia, dores vagas no tórax, abdome, ombros, região lombar, etc.). A ansiedade está freqüentemente associada. Em idosos, principalmente, as queixas de caráter hipocondríaco costumam ser muito comuns.

\section{Alterações dos rimos circadianos}

Muitas funções circadianas encontram-se alteradas nas depressões, a exemplo da regulação da temperatura e do ritmo de produção do cortisol. Entre as alterações mais conspícuas estão aquelas relacionadas ao ritmo do sono. Segundo Akiskal, ${ }^{6}$ cerca de dois terços dos pacientes deprimidos têm diminuição da latência para o início do sono REM ("Rapid Eyes Movements"). As formas ditas "melancólicas" da depressão caracterizam-se, entre outros aspectos, pela piora matinal e pelo despertar precoce pela manhã.

\section{Características melancólicas}

O termo "melancolia" tem sido empregado, nas atuais classificações (como o DSM IV), para designar o subtipo anteriormente chamado de "endógeno", "vital", "biológico", "somático" ou "endogenomorfo" de depressão. Considerado por muitos como o "protótipo" ou síndrome nuclear das depressões, a melancolia - ao contrário de outras formas de depressão - parece constituir-se em um grupo mais homogêneo, que responde melhor a tratamentos biológicos, e para o qual os fatores genéticos seriam os principais determinantes. Parker e cols. ${ }^{5}$ chamam a atenção para a importância das alterações psicomotoras na melancolia, para eles a principal característica desse quadro nosológico. O conceito de melancolia no DSM-IV foi revisto, em relação ao do DSM-III-R, tornando-se mais preciso e definindo com mais rigor no subgrupo aqui estudado. ${ }^{7}$ Testes biológicos, como, por exemplo, o teste da supressão do cortisol pela dexametasona, são mais freqüentemente positivos nos quadros melancólicos do que em outros tipos de depressão.

\section{Características psicóticas}

Cumpre lembrar que o termo "psicótico", origem de tantas controvérsias em psiquiatria, tem três significados distintos: 1 . significado meramente descritivo, quando designa, por exemplo, quadros psiquiátricos onde ocorrem alucinações e delírios; 2. significado etiológico, quando designa quadros endógenos (determinados por tendências constitucionais do indivíduo), em contraposição àqueles determinados por fatores psicogênicos; e 3. significado que alude à gravidade (ou intensidade) do quadro. As atuais classificações, fugindo de preconceitos etiológicos, utilizam o termo psicótico apenas em sentido descritivo. Assim, a expressão designa, nesse contexto, aquelas formas de depressão onde ocorrem delírios e alucinações. Admite-se que essas formas cheguem a $15 \%$ dos quadros depressivos.
Os delírios depressivos considerados congruentes com o humor incluem delírios de culpa, de punição merecida, delírios de ruína e delírios nihilistas (que podem configurar a síndrome de Cotard, quando incluem negação de órgãos e negação da morte). Na depressão delirante as pessoas podem interpretar eventos triviais do cotidiano como evidências de defeitos pessoais, ao tempo em que se culpam de forma indevida e francamente inapropriada. Um paciente, por exemplo, culpava-se pela morte de um desconhecido, cujo féretro passou por sua rua; outra, uma senhora de meia idade, julgava ser a responsável pela paralisação das obras de uma ponte em sua cidade. Mais comumente, no entanto, o paciente recua no tempo, com a finalidade de se acusar por supostos delitos ou atos culposos do passado, remoendo escrúpulos indevidos. Os temas de ruína, quando delirantes, apresentam-se, de acordo com Bleuler, ${ }^{3}$ como: ruína do corpo (delírios hipocondríacos: a pessoa acredita, por exemplo, estar com o fígado "apodrecido", ou com determinados órgãos "tomados pelo câncer”); ruína espiritual (delírios de culpa, com acusações por faltas ou pecados cometidos); e ruína financeira (delírios que envolvem temas de pobreza e miséria). A "escolha" do tema faz-se, certamente, em consonância com as características da personalidade do paciente. Por outro lado, podem ocorrer temas delirantes, aparentemente sem relação com o humor depressivo.

Os delírios incongruentes com o humor incluem temas de perseguição, e delírios de estar sendo controlado (estes, comumente associados a fenômenos "schneiderianos" de inserção e irradiação de pensamentos). Quando presentes, esses fenômenos incongruentes com o humor associam-se a um pior prognóstico, avizinhando-se, não raramente, dos estados ditos "esquizoafetivos".

As alucinações que acompanham os estados depressivos, quando presentes, são em geral transitórias e não elaboradas. Costumam ser, mais comumente, coerentes com o humor depressivo: vozes que condenam o paciente, imprecações do demônio, choro de defuntos, etc. Mais raramente, ocorrem alucinações não congruentes com o humor (sem relação aparente com os temas depressivos). As formas mais severas de depressão psicótica foram descritas por Kraepelin ${ }^{1}$ com o nome de "melancolia fantástica". Nessa forma aparecem intensos delírios e alucinações, alternando-se estados de violenta excitação com estados estuporosos, a par de leve obnubilação da consciência (essas formas são hoje dificilmente encontradas).

\section{Depressões catatônicas}

Diz-se que uma depressão tem características catatônicas quando o quadro clínico se caracteriza por intensas alterações da psicomotricidade, entre as quais: imobilidade quase completa, atividade motora excessiva, negativismo extremo, mutismo, estereotipias, ecolalia ou ecopraxia, obediência ou imitação automática. A imobilidade motora pode se apresentar como estupor (o chamado "estupor melancólico") ou ainda por catalepsia (flexibilidade cérea). Impõe-se aqui o diagnóstico diferencial cuidadoso, com a catatonia induzida por condição médica geral (por exemplo, encefalopatia hepáti- 
ca), por drogas ou medicamentos, e com a esquizofrenia catatônica. Cumpre notar que, nos tempos atuais, é muito raro encontrar-se um verdadeiro "estupor melancólico". As facilidades de diagnóstico e de tratamento quase sempre impedem a progressão a essas formas mais graves, que ainda em passado recente (particularmente antes da introdução do eletrochoque) ameaçavam a vida dos pacientes. Em pessoas jovens, o aparecimento de acentuada lentificação psicomotora e de formas sutis de estupor é quase sempre indicativo de doença bipolar, que freqüentemente acabará se manifestando mais tarde através de fases maníacas.

\section{Depressões crônicas (distimias)}

As depressões crônicas são geralmente de intensidade mais leve que os episódios de depressão maior. Mais que o humor francamente deprimido, os pacientes com depressão crônica (distimia) sofrem por não sentir prazer nas atividades habituais, e por terem suas vidas coartadas por uma espécie de morosidade irritável.

\section{Depressões atípicas}

Originalmente criado na Inglaterra, e posteriormente desenvolvido pelo grupo da Universidade de Columbia, em Nova York, o conceito de depressão "atípíca" refere-se (de modo muito típico) àquelas formas de depressão caracterizadas por: reatividade do humor, sensação de fadiga acentuada e "peso" nos membros, e sintomas vegetativos "reversos" (opostos aos da depressão melancólica), como aumento de peso e do apetite, em particular por carboidratos e hipersonia. Além disso, descreve-se como característica constante das pessoas sujeitas a esse tipo de depressão um padrão persistente de extrema sensibilidade à percepção do que consideram como rejeição por parte de outras pessoas. Episódios com características "atípicas" são mais comuns nos transtornos bipolares (I e II), no transtorno depressivo com padrão sazonal.

\section{Sazonalidade}

Especialmente no hemisfério norte, onde as estações do ano são bem definidas, verifica-se com clareza que algumas formas de depressão acentuam-se ou são precipitadas de acordo com um padrão sazonal; mais comumente as depressões desse tipo ocorrem no outono e no inverno. Muitos desses pacientes têm fases hipomaníacas na primavera, sendo classificados como do tipo bipolar II (depressões maiores e hipomania). Freqüentemente esses pacientes apresentam algumas características sobrepostas às da "depressão atípica": fadiga excessiva, aumento do apetite (em particular por carboidratos) e hipersonolência. O DSM-IV inclui o "padrão sazonal" como um especificador do tipo de depressão estudada.

\section{Classificações atuais dos estados depressivos CID-10}

A Classificação Internacional das Doenças, da Organização Mundial da Saúde, em sua décima revisão ${ }^{8}$, a CID-10, as- sim apresenta os transtornos do humor, em suas linhas gerais:

- F30 - Episódio maníaco (usado para episódio único de mania).

- F31 - Transtorno afetivo bipolar.

O transtorno afetivo bipolar pode ser classificado, de acordo com o tipo do episódio atual, em hipomaníaco, maníaco ou depressivo. Os episódios maníacos são subdivididos de acordo com a presença ou ausência de sintomas psicóticos. Os episódios depressivos são classificados de acordo com as regras descritas em F32. O transtorno afetivo bipolar inclui ainda os episódios mistos (F31.6).

- 12 F32 - Episódio depressivo (usado para episódio depressivo único).

O episódio depressivo pode ser, quanto à intensidade, classificado como: leve, moderado ou grave. Os episódios leves e moderados podem ser classificados de acordo com a presença ou ausência de sintomas somáticos. Os episódios depressivos graves são subdivididos de acordo com a presença ou ausência de sintomas psicóticos.

- F33 - Transtorno depressivo recorrente (tem as mesmas subdivisões descritas para o episódio depressivo).

-F34 - Transtornos persistentes do humor: F34.0 - Ciclotimia e F34.1 - Distimia.

A CID-10 inclui ainda códigos para "outros" transtornos do humor e para "transtornos não identificados".

\section{DSM-IV}

A Associação Psiquiátrica Americana, no DSM-IV, ${ }^{9}$ assim classifica os transtornos do humor:

Transtornos depressivos:

- 296.xx - Transtorno depressivo maior, que é subdividido em episódio único, ou recorrente.

- 300.4 - Transtorno distímico, que pode ser especificado de acordo com o tipo de início (precoce ou tardio), e de acordo com a presença ou ausência de características atípicas.

- 311 - Transtorno depressivo sem outra especificação (SOE).

Transtornos bipolares:

- 296.xx - Transtorno bipolar I.

O transtorno bipolar I inclui a ocorrência de episódio maníaco único. O DSM IV pede que se especifique o tipo do episódio mais recente: hipomaníaco, maníaco, depressivo, misto, ou inespecificado.

- 296.89 - Transtorno bipolar II (hipomania associada a pelo menos um episódio depressivo maior). Especificar se o episódio atual (ou mais recente) é hipomaníaco ou depressivo.

- 301.13 - Transtorno ciclotímico

- 296.80 - Transtorno bipolar sem outra especificação (SOE)

- 293.83 - Transtorno do humor devido a condição médica geral

•___ _ - Transtorno do humor induzido por substâncias (referir os códigos específicos para cada substância).

296.90 - Transtorno do humor sem outra especificação (SOE).

O DSM IV fornece ainda, em seu apêndice B, conjuntos de critérios para estudos adicionais. No que concerne os transtornos do humor, devem ser lembrados: transtorno depressivo menor, transtorno depressivo breve recorrente, transtorno misto de ansiedade-depressão e transtorno da personalidade depressiva. 


\section{Críticas ao conceito de "transtorno depressivo maior"}

O conceito de depressão maior, como aparece no DSM-IV, é excessivamente abrangente, e por isso mesmo, pouco preciso. Abarca provavelmente uma gama muito heterogênea de condições, que vão desde as fronteiras da normalidade (reações de luto ou tristeza normal) até aquelas formas mais graves de depressão, para as quais provavelmente concorrem fatores mais biológicos (adquiridos e/ou geneticamente determinados). Para o diagnóstico de "Transtorno Depressivo Maior", de acordo com o DSM-IV, basta que a pessoa apresente "humor deprimido ou perda de interesse ou prazer, durante um período de duas semanas", mais quatro sintomas de uma lista de nove (ou mais três sintomas, se os dois primeiros estiverem presentes). Assim, por exemplo, se uma moça que brigou com o namorado apresentar tristeza e perda de energia por 15 dias, além de mais três sintomas, como insônia, perda de energia e capacidade diminuída de se concentrar, terá preenchido critérios para "Transtorno Depressivo Maior". Um conceito tão amplo certamente não contribui para que se testem hipóteses sobre a etiologia das depressões, resposta a tratamentos biológicos, etc. Não serve tampouco para auxiliar na decisão de se medicar ou não a pessoa que preencha tais critérios. Já o conceito de melancolia é muito mais preciso e, por essa razão, tem maior valor preditivo quanto, por exemplo, à resposta terapêutica a antidepressivos e ao eletrochoque.

\section{Depressão e o espectro dos transtornos bipolares}

Assiste-se hoje, indubitavelmente, à redescoberta da obra de Kraepelin. ${ }^{1}$ Os critérios diagnósticos adotados pela Associação Psiquiátrica Americana (DSM IV) e pela Organização Mundial da Saúde (CID 10) refletem, em suas linhas gerais, a nosologia kraepeliniana. Também no âmbito das afecções do humor (transtornos afetivos) verifica-se, em aspectos fundamentais, o retorno às concepções de Kraepelin. Em 1921, tratando da definição da "insanidade maníaco-depressiva", Kraepelin escreveu:

"A insanidade maníaco-depressiva, como descrita nesse capítulo, inclui, por um lado, o domínio completo da chamada insanidade periódica e circular, e por outro lado inclui a mania simples, a maior parte dos estados mórbidos designados como melancolia, e também um número não desprezível de casos de amência. Finalmente, incluímos aqui certos coloridos leves e sutis do humor, alguns dos quais periódicos, outros continuamente mórbidos, os quais, se por um lado podem ser encarados como o rudimento de doenças mais severas, por outro lado passam, sem limites nítidos, para o campo da predisposição pessoal. No curso dos anos eu me tornei mais e mais convencido de que todos os estados acima mencionados representam apenas manifestações de um único processo mórbido."

Retomando a abordagem clássica de Kraepelin, Akiskal tem, em diversas publicações, ${ }^{6,10,11}$ enfatizado a importância do espectro da doença bipolar. Esse espectro incluiria desde as formas típicas da doença bipolar (bipolar I, com pelo menos uma fase maníaca), passando pelas depressões associadas à hipomania (bipolar II) até as depressões recorrentes, sem hipomania espontânea, mas frequientemente associadas ao temperamento hipertímico e/ou à história de transtorno bipolar na família. Estes últimos casos são chamados de "bipolar III" ou de "pseudo unipolares", na terminologia de Akiskal. Admite-se hoje, em geral, a existência de numerosas formas de transição entre estados depressivos e maníacos, incluindo suas formas mitigadas, que esbarram na fronteira dos chamados "temperamentos hipertímicos" e "depressivos". Por outro lado, muitos pacientes exaltados, com quadros psicóticos cíclicos, freqüentemente caracterizados por curso bifásico (alguns incluindo características psicóticas incongruentes com o humor) pertencem, na verdade, ao espectro bipolar, o que se depreende pela história familiar (bipolar) e resposta ao tratamento com estabilizadores do humor. De fato, muitos dos pacientes chamados "esquizoafetivos" concentram-se em famílias de pessoas com quadros afetivos bipolares típicos. ${ }^{12}$

O DSM IV tornou "oficial" o conceito de "transtorno bipolar II", incluindo na classificação americana os quadros de hipomania associados a episódios depressivos maiores (um ou mais episódios depressivos maiores, acompanhados pelo menos por um episódio hipomaníaco). Nas versões anteriores do DSM (DSM III e DSM III R), tais quadros - mais frequientes que os de tipo bipolar I - eram classificados apenas como "transtorno bipolar sem outra especificação- $S O E^{\prime}$.

O temperamento dos pacientes bipolares II e III, quando avaliado fora das crises, é freqüentemente ciclotímico, isto é, caracterizado por leves depressões que se alternam com hipomanias. Nos bipolares III a mudança para a hipomania não é observada espontaneamente. Muitas vezes ocorrem fases hipomaníacas, ou maníacas, em decorrência do uso de antidepressivos ou eletroconvulsoterapia. Cumpre notar que muitos desses pacientes têm história familiar de transtorno bipolar ou temperamento pré-mórbido hipertímico. Considerando-se que muitas vezes é difícil obter história fidedigna quanto a antecedentes familiares de bipolaridade, o diagnóstico basear-se-á, muitas vezes, na presença de temperamento hipertímico ou ciclotímico, associado a depressões recorrentes, para que se inclua o paciente dentro do "soft bipolar spectrum". Observe-se que, entre os ciclotímicos, são relativamente poucos $(6 \%)$ os que desenvolvem mania. A maioria desenvolverá quadros de depressão maior, aproximando-se dos bipolares de tipo II. Entre as depressões leves e crônicas, a importância do "espectro" é corroborada pelo fato de que um em três pacientes com diagnóstico de "distimia", observados prospectivamente, desenvolvem hipomania, caracteristicamente depois da farmacoterapia com antidepressivos. ${ }^{13}$ Os episódios depressivos daqueles pertencentes ao "espectro bipolar" tendem a se caracterizar por hipersonolência e hiperfagia, embora a insônia possa ocorrer, sobretudo em episódios mistos.

As flutuações do humor observadas nos bipolares II e III freqüentemente dão origem a crises na profissão, na vida familiar e no relacionamento social. Não por acaso, esses pacientes, sujeitos a períodos de exaltação do humor e liberação dos impulsos sexuais e agressivos, são erroneamente classificados como tendo transtornos da personalidade (borderline, narcísico e histriônico). Freqüentemente, o abuso e a dependência do álcool e de outras drogas ocorre como "complicação" das doenças do espectro bipolar, pela freqüência com que essas substâncias são usadas como autotratamento. 


\section{Os limites da depressão}

\section{Limites com os transtornos da personalidade}

A distinção entre um transtorno psiquiátrico propriamente dito (eixo I do DSM-IV) frente aos transtornos da personalidade (eixo II) reveste-se da maior importância, por suas consequiências práticas e teóricas. Considerada portadora de uma "doença”, a pessoa passa a merecer considerações diagnósticas, tratamento, e cuidados sociais. Rotulada como portadora de um "distúrbio da personalidade", a pessoa passa muitas vezes a ser alvo do nihilismo terapêutico e vítima de preconceitos morais. Na melhor das hipóteses, passa a ser vista simplesmente como "um pessoa bizarra", acautelando-se os demais frente às suas "atuações" e "manipulações", principalmente se o diagnóstico for de um dos seguintes transtornos: "borderline", anti-social, narcísico e histriônico. Segundo Akiskal, ${ }^{14}$ cerca da metade a dois terços dos pacientes classificados como "borderline" pertenceriam ao grupo das doenças do humor (afetivas), sendo, em sua maioria, integrantes do "espectro bipolar". Muitos desses pacientes caracterizam-se por ter uma biografia assaz tumultuada, cujo traço mais estável é a instabilidade nas relações afetivas, no trabalho, e na vida em geral. Freqüentemente, essas pessoas passam da "calmaria" afetiva à "tempestade" das automutilações e das tentativas de suicídio. O abuso e a dependência de drogas freqüentemente se associam ao quadro.

\section{Limites com outros diagnósticos}

O diagnóstico dos estados depressivos deve levar em conta, antes de mais nada, se os sintomas depressivos são primários ou secundários a doenças físicas e/ou ao uso de drogas e medicamentos. O DSM IV contém o item 293.83 - Transtorno do humor devido a uma condição médica geral para descrever esses casos. O DSM IV traz também critérios para o diagnóstico de Transtorno do humor induzido por substância. A tabela 1 enumera alguns agentes farmacológicos e doenças físicas associadas ao desencadeamento de estados depressivos.

No campo da nosologia psiquiátrica, além dos transtornos da personalidade (já abordados) devem-se levar em conta, entre outros, os seguintes diagnósticos diferenciais: transtornos de ansiedade; alcoolismo e outras farmacodependências; transtornos esquizofrênicos, quadros esquizofreniformes e a chamada doença esquizo-afetiva; quadros demenciais.

\section{Tabela 1 - Principais doenças e agentes farmacológicos associados ao desencadeamento de estados depressivos ${ }^{14-16}$}

Agentes farmacológicos

Anti-hipertensivos: reserpina, alfa-metil-dopa, propranolol e clonidina; Neurolépticos, Antiparkinsonianos: levodopa, carbidopa, amantadina; Corticosteróides; Interrupção do uso de anfetamina, cocaína e álcool; Outros: cicloserina, vincristina, vinblastina, cimetidina, indometacina, etc.

Doenças endócrinas

Tireóide: hipo e hipertireoidismo; Paratireóide: hiperparatireoidismo; Hipófise: hipopituitarismo; Supra-renal: hipercortisolismo e doença de Addison; Pâncreas: diabetes mellitus

Doenças neurológicas Esclerose múltipla, Parkinson, epilepsia, apnéia de sono, tumores, doença cérebro-vascular, demências

Doenças do colágeno Lupus eritematoso, artrite reumatóide

Doenças nutricionais Pelagra, anemia perniciosa, hipervitaminose A, beri-beri, etc.

Doenças infecciosas Sífilis terciária, toxoplasmose, mononucleose, hepatite, encefalite, AIDS, etc.

\section{Referências bibliográficas}

1. Kraepelin E. Dementia Praecox, Manic Depressive Insanity and Paranoia (1921). Translated by Barclay RM. In: Robertson GM, editor. Birminham: The Classics of Medicine Library. Reedição. Edinburgh: E \& S Livingstone, 1989.

2. Sedler MJ. Falret's discovery: the origin of the concept of bipolar affective illness. American Journal of Psychiatry 1983;140:1127-33.

3. Bleuler E. Psiquiatria. Rio de Janeiro: Guanabara Koogan; 1985.

4. Widlöcher DJ. Psychomotor retardation: clinical, theoretical and psychometric aspects. Psychiatric Clinics of North America 1983;6:27-40.

5. Parker G, Hadzi-Pavlovic D, Wilhem K, Hickie I, Brodaty H, Boyce P, et al. Defining melancholia: properties of a refined sign-based measure. British Journal of Psychiatry 1994;164:316-26.

6. Akiskal HS. Mood disorders: clinical features. In: Kaplan HI, Sadock BJ, editors. Comprehensive Textbook of Psychiatry. 6th ed. Baltimore (MD): Williams \& Wilkins; 1995. p. 1123-52.

7. Lafer B, Nierenberg AA, Rosenbaum JF, Fava M. Outpatients with DSM-IIIR versus DSM IV Melancholic Depression. Comprehensive Psychiatry 1996;37(1):37-9.

8. World Health Association. The ICD-10 Clasification of Mental and Behavioural Disorders. Clinical descriptions and diagnostic guidelines. Geneva: World Health Organization; 1992.

9. American Psychiatric Association. Diagnostic and Statiscal Manual of Mental
Disorders. 4th ed. Washington, DC: American Psychiatric Association; 1994. 10. Akiskal HS, Djenderedjian AH, Rosenthal RH, Khani MK. Cyclothymic disorder: validating criteria for inclusion in the bipolar affective group American Journal of Psychiatry 1977;134:1227-33.

11. Akiskal HS. The prevalent clinical spectrum of bipolar disorders: beyond DSM IV. Journal of Clinical Psychopharmacology 1996;16(2) Suppl 1:4-14.

12. Gershon ES, Hamovit J, Guroff JJ. A family study of schizoaffective, bipolar I, bipolar II, unipolar, and control probands. Archives of General Psychiatry 1982;39: 1157-67.

13. Rosenthal TL, Akiskal HS, Scott-Strauss A, Rosenthal RH, David M. Familial and developmental factors in characterologic depressions. Journal of Affective Disorders 1981;3:183-92.

14. Akiskal H.S. Temperament, personality and depression. In: Hippius H, Stefanis C, editors. Research in Mood Disorders: An Update. Gottingen: Hogrefe \& Hubes; 1994. p. 45.

15. Goodwin FK, Jamison KR. Manic-Depressive Illness. New York: Oxford University Press; 1990.

16. Jefferson JW, Greist JH. Mood disorders. In: Hales RE, Yudofsky SC, Talbott JÁ, editors. Textbook of Psychiatry. 2nd ed. Washington, DC: American Psychiatric Press; 1994. p. 465-94.

Correspondência José Alberto Del Porto

R. Leonardo Nunes, 93 - São Paulo, SP. CEP: 04039-010 